\title{
Matching strategies of teachers and schools in general equilibrium
}

\author{
Tom Ahn
}

\section{Correspondence:}

thomas.ahn@uky.edu

Department of Economics,

University of Kentucky, 302B

Mathews Bldg., Lexington, KY

40506, USA

\begin{abstract}
I use a structural matching model, North Carolina public school data, and a survey of teachers' career plans to analyze schools' and teachers' behaviors in the teacher transfer market. Results show that mid-career teachers with better pre-service qualifications are the most eager to search, different types of teachers and schools have different search strategies, and the market is turbulent, characterized by search friction and large movements of teachers to better, worse, or comparable schools. The market is not as stable and orderly as it may first appear. Simulations show that simple policies to direct teacher transfers are at best inefficient.
\end{abstract}

Jel codes: 124 ; J48; J62

Keywords: Matching; Teacher transfers; Ability sorting

\section{Introduction}

While teacher mobility and its impact on education production continues to be debated and actively researched, two important features of the teacher labor market in the United States emerge from the literature and the data: a) the teacher labor market is starkly segmented, with inexperienced teachers isolated in poor, underachieving schools, and b) a relatively stable job-queuing process seems to exist.

Simple summary statistics of teacher characteristics in most administrative data sets reveal that highly-qualified and experienced teachers are concentrated in schools that have high academic performance and low proportions of students of traditionally disadvantaged groups. Poor, inner-city schools tend to be staffed by teachers with the least amount of experience. The literature has shown that clear stratification of teachers exists along dimensions of undergraduate institution selectivity, experience, subject matter, and certification status (Darling-Hammond 2001, Boyd et al. (2002), and Table 1 in this study).

In addition, there is almost no wage differential across schools (at least within a state). Because schools do not compete on wages, teacher assignments are differentiated by non-monetary characteristics. Transfer rules (both explicit and implicit), which are negotiated between teachers and districts, tend to favor teachers with seniority. No wage differences across jobs should, all else equal, decrease the search rate of teachers. Seniority-based transfer rules should lead to a positive relationship between experience and search (and transfer) rate. More experienced teachers should move to schools with better non-monetary characteristics.

(c) 2015 Ahn; licensee Springer. This is an Open Access article distributed under the terms of the Creative Commons Attribution License (http://creativecommons.org/licenses/by/4.0), which permits unrestricted use, distribution, and reproduction in any medium, provided the original work is properly credited. 
Table 1 Summary statistics: administrative data

\begin{tabular}{|c|c|c|c|c|c|}
\hline Demographics & \multirow{2}{*}{$\begin{array}{l}\text { Stayers } \\
0.135\end{array}$} & \multirow{2}{*}{$\begin{array}{l}\text { Transfers } \\
0.141\end{array}$} & \multirow{2}{*}{$\begin{array}{l}\text { New } \\
0.119\end{array}$} & \multicolumn{2}{|c|}{$\Delta$ (Std. Err.) } \\
\hline Minority & & & & 0.006 & $(0.011)$ \\
\hline Female & 0.911 & 0.888 & 0.889 & $-0.023^{* *}$ & $(0.010)$ \\
\hline MA degree & 0.281 & 0.273 & 0.214 & -0.008 & $(0.014)$ \\
\hline Certified & 0.104 & 0.087 & 0.007 & $-0.017^{*}$ & $(0.009)$ \\
\hline \multicolumn{6}{|l|}{ Experience } \\
\hline Low (1 - 3 years) & 0.237 & 0.293 & & $0.056^{* * *}$ & $(0.014)$ \\
\hline Mid (4 - 10 years) & 0.390 & 0.443 & & $0.053^{* * *}$ & $(0.015)$ \\
\hline High (10 + years) & 0.373 & 0.264 & & $-0.109 * * *$ & $(0.015)$ \\
\hline \multicolumn{6}{|l|}{ Year (t-1) } \\
\hline Bad school & 0.130 & 0.212 & & $0.082^{* * *}$ & $\overline{(0.011)}$ \\
\hline Good school & 0.870 & 0.788 & & & \\
\hline School minority \% & 0.420 & 0.488 & & $0.068^{* * *}$ & (0.009) \\
\hline School poverty \% & 0.502 & 0.543 & & $0.041^{* * *}$ & $(0.007)$ \\
\hline School female \% & 0.488 & 0.487 & & -0.001 & $(0.001)$ \\
\hline \multicolumn{6}{|l|}{ Year (t) } \\
\hline Bad school & 0.130 & 0.149 & 0.170 & $0.019^{*}$ & $(0.011)$ \\
\hline Good school & 0.870 & 0.851 & 0.830 & & \\
\hline School minority \% & 0.391 & 0.412 & 0.452 & $0.022^{* *}$ & $(0.009)$ \\
\hline School poverty \% & 0.493 & 0.485 & 0.497 & -0.008 & $(0.007)$ \\
\hline School female \% & 0.468 & 0.468 & 0.468 & -0.001 & $(0.001)$ \\
\hline Observations & 10260 & 1136 & 2011 & & \\
\hline
\end{tabular}

NCERDC data from 2005/06 and 2006/07. School poverty $\%$ is the percentage of student population that receives free or reduced price lunch. 'Bad' schools are low-performing, and 'good' schools are high-performing schools. See end-note 16 for details. $\Delta$ is the difference in means between the Transfers and the Stayers. Difference in means is statistically significant from zero at $* 10 \%$ level, $* * 5 \%$ level, and ${ }^{* * *} 1 \%$ level, respectively.

The picture that emerges is one of a classic job queueing mechanism, where teachers who initially match with an undesirable school wait until seniority rules allow them to move up the job quality ladder to match with better schools. Placing teachers based largely on seniority will most likely lead to sorting that benefits teachers, and not necessarily students $^{1}$. Since teachers improve with experience, a queueing mechanism concentrates inexperienced (and as-of-yet less productive) teachers into schools populated with disadvantaged students. As these teachers become more productive, they will then be matched with students at better schools. Not only can this further widen the academic gap between the 'haves' and the 'have-nots,' the fact that the higher-achieving students reap the benefits (of teacher experience) built on teachers learning from their mistakes while teaching disadvantaged students is troubling. This understanding of the teacher labor market has led policy makers, practitioners, and administrators to advocate to eliminate or at least minimize such teacher transfers through scholarly work, position papers, lawsuits, or policy changes ${ }^{2}$.

In this study, I show that our understanding of the teacher labor market may be incomplete, leading to incorrect policy recommendations designed to curtail the loss of experienced teachers from under-performing schools. I analyze the teacher labor market where a teacher decides to search for a new school, and a school looks for a teacher to fill a vacancy, using the North Carolina public education administrative data set and the Working Conditions Survey (WCS). In the theory model, a teacher decides to search 
in a particular school market, and a school searches in a particular teacher market. The teacher searches in a school market based on a) her utility at the new school conditional on matching and b) her probability of finding a match in the market. The school searches in a teacher market based on a) its utility of matching with that teacher (type) and b) its probability of finding a teacher in that market. Any seniority-based hiring preferences should be partially reflected in how strongly schools search for highly experienced teachers.

I then estimate the structural matching model to find the following ${ }^{3}$ :

a) Teachers who are mid-career, with 4 - 10 years of experience, face the lowest cost of entry to engage in search. Although it is apparent from the data that more mid-career teachers successfully transfer to a different school, the WCS reveals that their rate of entry into the transfer market is no higher than teachers with less than 4 years of experience. The structural model is required to separate the likelihood of entering the transfer market, the cost of entering the transfer market, the probability of successfully matching with a new school, and the utility gain from the match. Separating the search process in this way reveals that mid experience teachers face the lowest entry cost into the transfer market. However, this low barrier to entry results in too much competition, somewhat dampening the attractiveness of the search market. In addition, teachers with better preservice qualifications (such as advanced degrees or certification) are more likely to be looking to transfer. Again, this is not obvious from the data, as teachers who transfer and those that do not move (whether voluntarily or involuntarily) look very similar in terms of pre-service qualifications.

b) When teachers decide to search, their search strategies differ depending on the teachers' status. Teachers from low-achieving schools across all experience levels behave similarly, searching for a good school about $88 \%$ of the time. Teachers from high-achieving schools have differing search strategies, depending on their level of experience. While mid and high level experience teachers focus search on high-achieving schools, teachers with low experience spend about $36 \%$ of the time searching for a match with a low achieving school. I speculate that this may be due to involuntary separation of these non-tenured teachers from their original school.

c) Different types of schools have different strategies to recruit teachers. A low achieving school will search $80 \%$ of the time for teachers who have at least 4 years of education, regardless of whether they originate from high or low-achieving schools. On the other hand, high-achieving schools will focus $75 \%$ of their search on teachers with at least 4 years of experience from high-achieving schools. These search strategies reveal that new teachers are acceptable substitutes for teachers with only a few years of experience. Lowachieving schools in particular are willing to accept the risks of attempting to match with a more experienced teacher even if it means that they will, very often, fail and be forced to 'settle' for a new teacher.

d) The observed changes in teacher quality distribution due to transfers understate the true extent of labor market volatility and search friction. Conditional on searching for a new position, even a teacher with the best qualifications (high experience and originating from a good school) succeeds in finding a match with a highachieving school only $64 \%$ of the time. Similarly, a high-achieving school manages to match with a highly experienced teacher from a high-achieving school only $33 \%$ of the time. 
Based on a simplistic, incomplete picture of teacher transfers where the market operates through a rigidly stable queuing process, introducing simple changes to seniority rules could lead to a more efficient (and/or more equitable) allocation of teachers, leading to improvements in poor schools that lose these experienced teachers ${ }^{4}$.

Policy simulations using the parameter estimates from the structural model to investigate the general equilibrium impact of policies to deter the transfer of experienced teachers yields the following:

a) Decreasing vacancies in desirable schools by $15 \%$ leads to movement of low and high experienced teachers to less desirable schools. However, mid experienced teachers actually move away from these schools. Entry of teachers into the transfer markets is broadly suppressed, but the overall impact on improving teacher quality at poor schools is minimal, as the largest change in the distribution of teachers is a reduction in the number of newly minted teachers and an increase in the number of low experience teacher. As schools are shown below to value low experience and no experience teachers about equally, low achieving schools do not benefit much from the policy.

b) Increasing the desirability of low achieving schools to mid-career teachers by $20 \%$ leads to positive effects, with more teachers of all experience levels ending up at these schools. Teachers already at these schools refrain from engaging in search, and more teachers at better performing schools enter the transfer market to look for openings in these newly improved schools. However, the overall impacts are fairly modest, with the number of mid experience teachers increasing by about $7 \%$. Given the large costs of implementation to impact a relatively small number of schools, this policy seems unlikely to be implemented.

The next subsection describes the teacher transfer market in detail and justifies the need for a structural matching model for this analysis. Section 2 describes the two data sets used in the estimation. Section 3 describes the econometric model in detail, and the estimation strategy is presented in Section 4. Section 5 presents and discusses the results which are used in the policy simulations in Section 6. Conclusions follow in Section 7.

\subsection{Teacher Transfers and the Matching Market}

Teachers are mobile. As I show in the data section, even teachers with high levels of experience (and long tenures at a school) will move. Since a principal will, on average, lose 10 to $20 \%$ of her workforce each year, she must be searching annually for replacements. In other labor markets, wage differentials across jobs would play a prominent role in how employers and employees search for each other, with wages moving up or down in response to changes in labor demand and supply to clear the market.

In the education labor market, however, wages are flat across schools (with the exception of small district-specific differences $)^{5}$ and change only with experience level, certification, and advanced degrees. That is, the price of labor is exogenous. These individual pay increases are usually based on characteristics inherent to the teacher and are portable $^{6}$. Therefore, a principal cannot recruit on wage but must seek to attract teachers based on the characteristics of her school ${ }^{7}$. In addition, because teacher salary is not paid by the principal but at the district level, teachers are cost-neutral to the principal. She will recruit a teacher based on her characteristics and not the wage that will have to be paid.

In addition, restrictive hiring rules may tie a principal's hands in searching for teachers to fill vacancies. Seniority-based hiring is thought to impact a school negatively by 
some principals as well as many education experts, yet many times they are powerless to prevent such transfers (Ballou 1999). Teachers' contracts are perceived to inhibit the principals' ability to effectively select their labor force. At the same time, involuntary transfers that are initiated by the principal, usually to jettison ineffective teachers, appear to be only a minor component of the teacher labor market (Nelson 2006). Summary statistics from administrative data sets (See Table 1 in this study, for example) show that when teachers transfer, in general, they move to 'better' schools, and that these teachers tend to be at mid-career or later, with at least 4 years of experience. The literature has shown that disadvantaged schools have difficulty recruiting teachers and are less selective in hiring, while advantaged schools tend to have a surplus of applicants, allowing them to be more selective. (Darling-Hammond 2001 and Boyd et al. 2002).

Accountability legislation may also influence a principal's recruiting decision by introducing market pressures in terms of monetary rewards or sanctions ${ }^{8}$. Some districts in North Carolina have tried to actively prevent the transfer of teachers into 'desirable' schools of high academic achievement and restrict transferring principals from 'poaching' too many teachers from their origin schools (Helms 2005).

In North Carolina, teachers who wish to transfer to a different school submit their names to a central clearing house, but the process by which teachers and schools actually match are different for each individual case. While there may be some matching that occurs according to a mechanical rule-set, at least in the majority of cases, it appears that teachers and principals do actively search for each other. Principals will strategically time posting of open positions or reach out to certain teachers to impact recruiting outcomes. Some administrators cultivate a draconian image or send out negative observable signals to discourage potential bad matches (Ballou 1999). Conversations with education policy practitioners in North Carolina reveal that ambitious principals in North Carolina aggressively search through transfer applicant lists to look for the most desirable candidates. Indeed, the anecdotal evidence points to the existence of a complex and active transfer market.

All that can be said with certainty is that some teachers and schools search for each other based on observable characteristics. Other teachers are content to stay at their school (for the time being, at least). Some teachers and schools succeed in matching, and these are observed as transfers in the data. Other teachers and schools fail to match, in which case there is no movement. The process is decentralized, with the state providing only a platform for both sides of the markets to post their availability ${ }^{9}$.

If the surface teacher labor market appears as an orderly job queuing process, while there is an active, turbulent job search market underneath, our understanding of the teacher labor market would be incomplete. If the model of teacher transfer used to make policy recommendations does not adequately capture the churning of the labor market, instituting simple policies to stop or slow the perceived movement of teachers up the job quality ladder may not accomplish the goal of keeping experienced teachers where they are most needed.

With the lack of a price mechanism to sort teachers, the complexity of the transfer process, and no detailed survey data to track teacher and school search behavior, a structural matching market framework is the most natural and tractable model for the teacher transfer decision as described above. Some previous studies have looked at the transfer decision in the context of a matching model. Boyd et al. (2013) showed that teachers are 
particularly sensitive to the distance between the school and their place of birth or high school attended. In another study where the authors had detailed information about all transfer applicants, Boyd et al. (2011) determined that teachers that are most likely to apply for a transfer look different from those who are most likely to find a match.

Two common challenges in estimating a matching model are the difficulties in defining a) who is searching and b) the choice-set over which she searches (such that estimation is tractable). Information to identify teachers (and schools) that are searching can be difficult to obtain ${ }^{10}$. In the absence of this information, the entire sample is usually assumed to be searching. For this study, I am able to extract aggregate statistics on searching teachers at the school-level from a separate survey of teachers, which will be used to augment the individual matching data from the North Carolina administrative dataset.

Defining the choice-set to allow empirical estimation usually requires multidimensional logit or probits (if the sample size is small enough), simulated maximum likelihood estimation, or alternative frameworks such as the use of maximum score estimators (MSE) ${ }^{11}$. I define the choice-set as a limited number of markets that teachers and schools may search over ${ }^{12}$. In the model, neither teachers nor schools are bound by geography in searching for each other. Teachers observe all openings in the state, and schools observe all applicants in North Carolina. Teachers choose to search for a certain type of school ('good' or 'bad', as defined below in the Data section). Schools choose to search for a certain type of teacher (defined by the teacher's experience and whether she is currently at a good or bad school). Both teachers and schools evaluate the utility gain if they search in a particular market and succeed in matching. The probability of success depends on the number of teachers of her type searching for her preferred school type and the number of schools of her preferred type searching for teachers of her type. Based on this calculation, teachers decide whether to search for a new position, which in turn, affects the probability of all other teachers and schools in finding a match ${ }^{13}$.

\section{Data}

I use an administrative data set for the North Carolina public school system from the 2005/06 and 2006/07 academic years. The data set contains information on all public schools, students, and teachers in North Carolina. The data is collected annually, and the capability exists to link students and teachers across years. What emerges is a relatively complete longitudinal picture of the entire North Carolina public school system. This allows me to track the movement of teachers into the labor market and between schools from year to year. Teachers located in a particular school in the 2005/06 academic year and located in a different school in the 2006/07 academic year are identified as transferring teachers.

In addition, I make use of the North Carolina Working Conditions Survey. This biennially administered anonymous survey queries all public school teachers and principals about their perception of the school environment. I use the 2006 survey, which was administered in April of that year. The timing of the survey is important for this study, as April will be just before a teacher officially commits to searching for a new position. The survey captures the teacher's labor market plans in the immediate future, asking whether she plans to continue teaching at the current school, seek better opportunities elsewhere (within or outside the current education district), or leave the profession ${ }^{14}$. The response rate for the 2006 WCS was approximately $60 \%$. Aggregate statistics across the 
administrative data and the WCS data for gender, minority status, and experience were qualitatively similar.

I focus on elementary school teachers in this study, as middle and high school teachers may have different career trajectories. I explicitly exclude teachers who leave the profession from both data sets. From the WCS, this is accomplished by dropping all teachers who answer that they will leave the profession. For the administrative data set, I stack the 2006/07, 2007/08, and 2008/09 data sets to isolate teachers who appear in the 2005/06 data set yet disappear from subsequent year data sets.

Of note for these two data sets is that they cannot be directly linked. Although teachers are identified up to the school level in the WCS, the individual observations cannot be linked to the administrative data set. Therefore, while it is possible to identify teachers who are successful in transferring to a new school (and therefore, were searching for a new position), those who remain at the same school can either be: 1) teachers who chose not to search or 2) teachers who searched but failed to match. The estimation will have to take this into account.

Some summary statistics from the administrative data set and the WCS are presented in Tables 1 and $2^{15}$. The first column of Table 1, labeled 'Stayer' contains summary statistics for teachers who remain at their current school across the two years of the data. The second column, labeled 'Transfers' summarizes characteristics of teachers who successfully move to a new school. The third column, labeled 'New,' contains information on teachers newly hired in the second year of the data. The final column, labeled ' $\Delta$,' calculates the difference in means between Transfers and Stayers.

I divide schools into two categories: low-performing and high-performing. The categories are based on the state's own system of evaluating schools based on its accountability system. Low-performing schools are those with less than $60 \%$ of their students reading and doing arithmetic at their grade levels. High-performing schools are those with more than $60 \%$ of their students performing at grade level ${ }^{16}$. In categorizing the schools, I use the school categorization from 2005/06 data and do not update the school categorization in year 2006/07 (when teachers show up in their new schools). This is because the information available to teachers when they are making the transfer decision is the school's status in 2005/06. Therefore, in Table 1 , the schools in each category in years $t-1$ and $t$ are identical.

Experience level is divided into low (1 to 3 years), mid ( 4 to 10 years), and high (more than 10 years) for this study ${ }^{17}$. Low level of experience represents nontenured teachers who are still relatively new to the job. Previous studies of teacher productivity have shown

Table 2 Percentage of teacher of type $j, k^{o}$ entering the transfer market: WCS dataset

\begin{tabular}{lc}
\hline Experience $(\boldsymbol{j})$, School Type $\left(\boldsymbol{k}^{\boldsymbol{0}}\right)$ & Pr. of Mkt. Entry \\
\hline Low experience, bad School & 0.480 \\
Mid experience, bad School & 0.444 \\
High experience, bad School & 0.330 \\
Low experience, good School & 0.334 \\
Mid experience, good School & 0.328 \\
High experience, good School & 0.224
\end{tabular}

Working Conditions Survey (WCS) data from 2006. The probability that a teacher of type $\boldsymbol{j}, \boldsymbol{k}^{\boldsymbol{o}}$ decides to search for a new position, where $j$ is the level of experience, and $\boldsymbol{k}^{\boldsymbol{o}}$ is the type of school where the teacher is currently employed. 'Bad' schools are low-performing, and 'good' schools are high-performing schools. 'Low' experience is 1-3 years, 'Mid' experience if 4-10 years, and 'High' experience is $10+$ years. See end-note 16 for details. 
that these teachers are, on average, lower performing compared to teachers with more experience, yet they make gains each year (Rivkin et al. 2005). Because of their probationary status, it may be easier to remove these teachers from the school if they severely under-perform. They also tend to leave the teaching profession at higher rates compared to teachers with more experience. As it can be seen from the data, they are not highly mobile (at least in their ability to transfer), most likely due to the limited options available to them. Mid levels of experience are tenured teachers who are continuing to see productivity gains, but at smaller and decreasing increments. These teachers tend to be the most mobile, and many will move to a more desirable school. High levels of experience are tenured teachers who are on the flat or even declining portions of the productivity curve. Although these teachers are less mobile compared to mid-level experienced teachers, they can be induced to search, as one quarter of all transfers are teachers from this category.

The general impression from Table 1 is that there is a slow, orderly process by which teachers move up the school quality ladder. New teachers with no experience enter the profession at a 'bad' school (at a higher proportion compared to incumbent teachers, at 0.17). As they gain experience, these teachers transfer to a 'good' school such that the proportion changes to 0.149 . Eventually, the proportion of teachers in bad schools converges to 0.13 . In Table 2, however, the high proportion of teachers who are searching for a new position annually hints at the possibility that the labor market is not as stable and orderly as Table 1 may imply. If roughly $40 \%$ of teachers are searching with less than half resulting in successful matches, there may be significant labor market friction ${ }^{18}$. Table 2 also reveals that low and mid experience teachers enter the transfer markets at almost identical rates, at about $45 \%$ and 33\% for teachers from 'bad' and 'good' schools, respectively. High experience teachers are least likely to engage in search.

\section{Model}

\subsection{Teachers}

Teachers are identified by a) group characteristics $(j \in J)$ and b) origin school characteristics $\left(k^{o} \in K\right)$. The probability of a $j$-type teacher from a $k^{o}$-type school matching with a $k$-type school is $P_{j, k^{\circ}}^{k}$. The deterministic portion of utility conditional on matching is given by $\mu_{j, k^{o}}^{k}$ for a $j$-type teacher from a $k^{o}$-type school transferring to a $k$-type school. The individual stochastic terms are defined by $\left\{v_{j, k^{o}}, \epsilon_{j, k^{o}}^{k}\right\}$. Note that the $v$ term is teachertype specific, while the $\epsilon$ term is match-specific. I assume that $v$ and $\epsilon$ are independently distributed and known to the teacher (but not to the econometrician).

The teacher makes two (sequential) decisions:

1. Whether to enter the transfer market or to forgo search altogether.

2. Conditional on deciding to enter, selecting which $k$-type school market to search in.

Deciding to search incurs an entry cost into the transfer market $K_{j, k^{o}}$, and deciding to move conditional on a match incurs a moving $\operatorname{cost} C_{j, k^{\circ}}^{k}$.

I set up the model in reverse. Conditional on deciding to search, a $j$-type teacher from a $k^{o}$-type school's expected utility of searching for a match with a $k$-type school is:

$$
E\left(U_{j, k^{o}}^{k} \text { Search }\right)=P_{j, k^{o}}^{k}\left(\mu_{j, k^{o}}^{k}-C_{j, k^{o}}^{k}+\epsilon_{j, k^{o}}^{k}\right)+\left(1-P_{j, k^{o}}^{k}\right)\left(\mu_{j, k^{o}}^{k^{o}}\right)
$$


Note that conditional on failing to match, the teacher merely takes the utility of staying at the current school without a match specific error term. Re-writing to isolate the error term gives:

$$
E\left(U_{j, k^{o}}^{k} \mid \text { Search }\right) / P_{j, k^{o}}^{k}=\mu_{j, k^{o}}^{k}+\frac{1-P_{j, k^{o}}^{k}}{P_{j, k^{o}}^{k}} \mu_{j, k^{o}}^{k^{o}}-C_{j, k^{o}}^{k}+\epsilon_{j, k^{o}}^{k}
$$

Including the expected utility of searching for a new school with the same observable characteristics $k^{o}$ yields:

$$
E\left(U_{j, k^{o}}^{k^{o}} \mid \text { Search }\right) / P_{j, k^{o}}^{k^{o}}=\frac{1}{P_{j, k^{o}}^{k^{o}}} \mu_{j, k^{o}}^{k^{o}}-C_{j, k^{o}}^{k^{o}}+\epsilon_{j, k^{o}}^{k^{o}}
$$

Assuming that the individual match errors are distributed as i.i.d. extreme value Type I, I can write the probability of a $j$-type teacher from a $k^{o}$-type school looking to transfer to a $k$-type school (assuming I could observe which type of school the teacher looks to match with) as a multinomial $\operatorname{logit}{ }^{19}$ :

$$
\operatorname{Pr}\left(k \mid j, k^{o}\right)=\gamma_{j, k^{o}}^{k}=\frac{\exp \left(\mu_{j, k^{o}}^{k}+\frac{1-P_{j, k^{o}}^{k}}{P_{j, k^{o}}^{k}} \mu_{j, k^{o}}^{k^{o}}-C_{j, k^{o}}^{k}\right)}{\sum_{k^{\prime}} \exp \left(\mu_{j, k^{o}}^{k^{\prime}}+\frac{1-P_{j, k^{o}}^{k^{\prime}}}{P_{j, k^{o}}^{k^{\prime}}} \mu_{j, k^{o}}^{k^{o}}-C_{j, k^{o}}^{k^{\prime}}\right)}
$$

\subsection{Schools}

Schools match with teachers in much the same manner, with one difference: if a school searches for a $j, k^{o}$-type teacher and does not match, the outside option (which is guaranteed) is with a newly minted teacher. I assume that a school does not explicitly search for a new teacher ${ }^{20}$. I assume that search cost is identical across all schools looking for all teacher types ${ }^{21}$. Specifying the utility of matching with a teacher with zero experience as $\mu_{k}^{0}$, the expected utility of a school of type $k$ matching with a teacher of type $j, k^{o}$ is:

$$
E\left(U_{k}^{j, k^{o}}\right)=P_{k}^{j, k^{o}}\left(\mu_{k}^{j, k^{o}}+\epsilon_{k}^{j, k^{o}}\right)+\left(1-P_{k}^{j, k^{o}}\right) \mu_{k}^{0}
$$

The probability of a $k$-type school getting a $j, k^{o}$-type teacher is ${ }^{22}$ :

$$
\operatorname{Pr}\left(j, k^{o} \mid k\right)=\gamma_{k}^{j, k^{o}}=\frac{\exp \left(\mu_{k}^{j, k^{o}}+\frac{1-P_{k}^{j, k^{o}}}{P_{k}^{j, k^{o}}} \mu_{k}^{0}\right)}{\sum_{k^{\prime}} \exp \left(\mu_{k^{\prime}}^{j, k^{o}}+\frac{1-P_{k^{\prime}}^{j, k^{o}}}{P_{k^{\prime}}^{j, k^{o}}} \mu_{k^{\prime}}^{0}\right)}
$$

Since I only observe successful matches, I next define a matching function to derive $P_{j, k^{o}}^{k}$

\subsection{Matching}

For simplicity, I assume a Cobb-Douglas matching function where the number of matches between a $j$-type teacher from a $k^{o}$-type school transferring to a $k$-type school is defined as:

$$
X_{\left\{j, k^{o}-k\right\}}=A\left(\gamma_{j, k^{o}}^{k} T_{j, k^{o}}\right)^{\alpha}\left(\gamma_{k}^{j, k^{o}} O_{k}\right)^{1-\alpha}
$$


where $T_{j, k^{o}}$ is the number of $j$-type teachers from $k^{o}$ schools who search for new positions, and $O_{k}$ is the number of teacher positions open from $k$-type schools. $A$ is a normalizing constant. Then, the probability of matching can be written as:

$$
\begin{aligned}
& P_{j, k^{o}}^{k}=A\left(\frac{\gamma_{k}^{j, k^{o}} O_{k}}{\gamma_{j, k^{o}}^{k} T_{j, k^{o}}}\right)^{1-\alpha} \\
& P_{k}^{j, k^{o}}=A\left(\frac{\gamma_{j, k^{o}}^{k} T_{j, k^{o}}}{\gamma_{k}^{j, k^{o}} O_{k}}\right)^{\alpha}
\end{aligned}
$$

It is worth noting that in this framework, the probability of matching with a newly minted teacher from the school side, $P_{k}^{0}$, is unidentified even if searching in this market were allowed. In the matching framework, both the number of searching teachers and schools are necessary to derive the matching probabilities. However, $T_{0}$, the number of newly minted teachers in the market is unidentified since those new teachers who failed to match are never observed.

\subsection{Teacher decision to enter the transfer market}

I assume that schools must fill empty positions. Teachers do have an option to not enter the transfer market ${ }^{23}$. I define the teacher's value of entering the transfer market $(V T)$ and not entering $(V N)$ as:

$$
\begin{aligned}
V T_{j, k^{o}} & =E\left(\sum_{k}^{K} \gamma_{j, k^{o}}^{k}\left(P_{j, k^{o}}^{k}\left(\mu_{j, k^{o}}^{k}-C_{j, k^{o}}^{k}+\epsilon_{j, k^{o}}^{k}\right)+\left(1-P_{j, k^{o}}^{k}\right)\left(\mu_{j, k^{o}}^{k^{o}}\right)\right)\right)-K_{j, k^{o}} \\
V N_{j, k^{o}} & =\mu_{j, k^{o}}^{k^{o}}
\end{aligned}
$$

At this point, I assume $E\left(\epsilon_{j, k^{o}}^{k} \mid P_{j, k^{o}}^{k}\right)=0 \forall k \in K$ to the teacher as well. The entry cost contains the error term $v$, which is distributed i.i.d. normal:

$$
K_{j, k^{o}}=z_{j, k^{o}}+v_{j, k^{o}}
$$

The $j$-type teacher from $k^{o}$-type school searches when $V T_{j, k^{o}}>V N_{j, k^{o}}$, so the number of $j, k^{o}$-type searchers $T_{j, k^{o}}$ equals:

$T_{j, k^{o}}=\sum_{j, k^{o}} 1\left(v_{j, k^{o}}>\sum_{k}^{K} \gamma_{j, k^{o}}^{k}\left(P_{j, k^{o}}^{k}\left(\mu_{j, k^{o}}^{k}-C_{j, k^{o}}^{k}\right)+\left(1-P_{j, k^{o}}^{k}\right)\left(\mu_{j, k^{o}}^{k^{o}}\right)\right)-\mu_{j, k^{o}}^{k^{o}}-z_{j, k^{o}}\right)$

Note that $v$ is teacher-type specific and not match specific. Because the WCS and the administrative data cannot be linked at the teacher level, it is impossible to discern whether some teachers are immobile by choice or by a failed search. To deal with this constraint of the data, I assume that the initial decision to enter the market is independent of the match specific error $(\epsilon)$ draws that the teacher observes when she chooses to search in particular school markets. The $v$ term is then interpreted as a shock that impacts only the entry cost for the teacher. For example, health, family, or financial reasons may change a teacher's willingness to uproot and move, which is unchanging across all school markets she can potentially search in.

\subsection{Teacher Decision to Quit}

I do not explicitly model a teacher quit decision in the model. Labeling the current school year as $t$ and the next school year as $t+1$, the search decision is made between $t$ and $t+1$. 
I assume that a teacher who has decided to leave the profession due to her unsatisfactory search outcome serves out her contract in year $t+1$ and exits in year $t+2$. More generally, I do not include the quit decision in the choice set for teachers because to exit the profession is a longer-term, career changing/ending decision that is dynamic in nature and ill-suited to a one-shot game model ${ }^{24}$. This assumption is tacitly confirmed by the fact that the fraction of teachers who identify themselves as planning on leaving the teaching profession in the WCS $(\approx 8.7 \%$ of the sample) is close to the actual fraction of teachers who are lost from the data between years $t$ and $t+1(\approx 9.7 \%$ of the sample).

\subsection{School decision to enter the transfer market}

While it is technically possible to write out the school's decision to search using the framework specified for the teacher search decision specified above, I choose to abstract away from the school decision. It seems that schools do not have much of a decision to make whether to search or not. If a class does not have a teacher assigned to it, the school must fill this position. While it may be feasible to not hire a teacher and distribute students into the remaining classes, it seems unclear what, if any, utility or education production function this decision would maximize. Conditional on the salary budget and salary for individual teachers being exogenous to the principal, I assume the principal would never decide not to search if a need exists ${ }^{25}$.

\section{Estimation}

The data available dictate the econometric model. Teachers can be identified up to the school-level, and minimal demographic characteristics are available in the WCS. In particular, using the WCS, I can discern what fraction of teachers of a certain type from each school decides to search for a new teaching position. However, I cannot link the teacher from the WCS to the NC administrative data. This means that I cannot directly link the entry-into-the-transfer-market decision to the search-in-a-particular-market decision individually. I divide teachers by the three experience levels defined in the data section as well as the origin school type. This identifies six unique types of teachers and two types of schools ${ }^{26}$. Origin school type should matter to teachers, because the assumption is that transferring teachers are referencing the type of school they came from, to judge whether they will be happier moving to a particular type of school. Origin school should also matter to the searching school as well, as an immediately observable signal of teacher quality. Significant parameter estimates on the origin type variable in the school's utility function seem to indicate that principals do use this information in selecting what markets to search in ${ }^{27}$.

The general strategy then is to break down the decision process into two sequential search decisions. In the first, using the WCS data, I extract the probability of entry into the transfer market by teacher type, which will be parametrized by the individual expected utilities of matching with the different types of schools (as well as failing to match and remaining in the current school). This will 'predict' the number of teachers who decide to search, which can be plugged into the probability of matching, which can then be plugged into the probability of searching in a particular market, conditional on deciding to search. Finally, these probabilities can be plugged back into the entry decision to generate the predicted number of searchers again. 
If a teacher of type $j$ from school type $k^{o}$ decides to enter the transfer market, the outcome is described in the WCS data as $S_{j, k^{o}}=1$. If the teacher decides to forgo search, $S_{j, k^{o}}=0$. Again, it is worth noting that from the teacher side, the sample excludes new teachers. The log likelihood for the entry decision is:

$$
\begin{aligned}
L_{s}= & \sum_{j, k^{o}}^{J, K} \sum_{i}^{T_{j, k^{o}}} I\left(S_{j, k^{o}}=1\right) \ln \Phi\left(\sum_{k}^{K} \gamma_{j, k^{o}}^{k}\left(P_{j, k^{o}}^{k}\left(\mu_{j, k^{o}}^{k}-C_{j, k^{o}}^{k}\right)+\left(1-P_{j, k^{o}}^{k}\right)\left(\mu_{j, k^{o}}^{k^{o}}\right)\right)-\mu_{j, k^{o}}^{k^{o}}-z_{j, k^{o}}\right) \\
& +\sum_{j, k^{o}}^{J, K} \sum_{i}^{T_{j, k^{o}}} I\left(S_{j, k^{o}}=0\right) \ln \left(1-\Phi\left(\sum_{k}^{K} \gamma_{j, k^{o}}^{k}\left(P_{j, k^{o}}^{k}\left(\mu_{j, k^{o}}^{k}-C_{j, k^{o}}^{k}\right)+\left(1-P_{j, k^{o}}^{k}\right)\left(\mu_{j, k^{o}}^{k^{o}}\right)\right)-\mu_{j, k^{o}}^{k^{o}}-z_{j, k^{o}}\right)\right),
\end{aligned}
$$

where $\Phi(\cdot)$ is the standard normal distribution function.

If a teacher of type $j$ from school $k^{o}$ transfers to a new school, the outcome is described in the administrative data as a match, $M_{j, k^{o}}=k$. If the teacher remains at her current school, $M_{j, k^{o}}=0$. The log likelihood for the matching model is then:

$$
\begin{aligned}
L_{m} & =\sum_{k}^{K} \sum_{j, k^{o}}^{J, K} \sum_{i}^{T_{j, k^{o}}} I\left(M_{j, k^{o}}=k\right)\left(\ln \gamma_{j, k^{o}}^{k}+\ln P_{j, k^{o}}^{k}+\ln \Phi\left(S_{j, k^{o}}=1\right)\right) \\
& +\sum_{j, k^{o}}^{J, K} \sum_{i}^{T_{j, k^{o}}} I\left(M_{j, k^{o}}=0\right) \ln \left(\sum_{k}^{K} \gamma_{j, k^{o}}^{k}\left(1-P_{j, k^{o}}^{k}\right) \Phi\left(S_{j, k^{o}}=1\right)+\left(1-\Phi\left(S_{j, k^{o}}=1\right)\right)\right) \\
& +\sum_{k}^{K} \sum_{j, k^{o}}^{J, K \backslash\{0\}} \sum_{i}^{S_{k}} I\left(M_{k}=j, k^{o}\right)\left(\ln \gamma_{k}^{j, k^{o}}+\ln P_{k}^{j, k^{o}}\right) \\
& +\sum_{k}^{K} \sum_{i}^{S_{k}} I\left(M_{k}=0\right) \ln \left(\sum_{j, k^{o}}^{J, K \backslash\{0\}} \gamma_{k}^{j, k^{o}}\left(1-P_{k}^{j, k^{o}}\right)\right)
\end{aligned}
$$

This first line of the likelihood function contributes the probability of observing a $j, k^{o}$ type teacher who searches and matches with a type $k$ school. The second line contributes the probability of observing a teacher of a certain type who does not match, which could arise because she failed to match or chose not to search. The third line contributes the probability of a school of a certain type matching with a certain type of teacher. The fourth line contributes the probability of a school failing to find a match and hiring a new teacher. The summation over the types of teachers $\left(j, k^{o}\right)$ in the third and fourth lines emphasizes the exclusion of new teachers.

Teacher side $\gamma_{j, k^{o}}^{k}$ and school side $\gamma_{k}^{j, k^{o}}$ choice probabilities are specified as multinomial logits. From the teacher side ${ }^{28}$ :

$$
\mu_{j, k^{o}}^{k}=\vec{\beta}^{k} x_{j, k^{o}}
$$

and from the school side:

$$
\mu_{k}^{j, k^{o}}=\overrightarrow{\beta^{j, k^{o}}} x_{k}
$$

I fix $\alpha=0.5$ to allow for symmetric friction from both the teacher and school side ${ }^{29}$.

During the first iteration, from the WCS data, I extract the number of searching teachers and the probability of entering the transfer market by teacher type $\left(T_{j, k^{o}}\right.$ and $\Phi\left(S_{j, k^{o}}=\right.$ $1)$, respectively). From the administrative data set, I extract the number of vacancies by school type $\left(O_{k}\right)$. The part of the likelihood for schools that do not match are defined as schools that hire new teachers. Therefore, $O_{k}$ is defined as the sum of transfers and new hires. Using these values, I maximize the log likelihood of the matching model $\left(L_{m}\right)$ while 
solving for the fixed point (at the teacher and school matching probabilities $\left(P_{j, k^{o}}^{k}\right.$ and $P_{k}^{j, k^{o}}$, respectively)). With these values in hand, I calculate the probabilities and expected utility values needed to maximize the log likelihood of the entry decision $\left(L_{s}\right)$ to generate the predicted number of teachers $\left(\widehat{T_{j, k^{o}}}\right)$ and the probability of entry $\left(\Phi\left(\widehat{S_{j, k^{o}}=1}\right)\right)$. This is iterated until convergence, defined below.

At each iteration $t$, a set of parameters, predicted probabilities, and number of searching teachers are estimated. The system converges when:

$\left\|\left\{\widehat{P_{j, k^{k}}^{k}}, \widehat{P_{k}^{j, k^{o}}}, \widehat{T_{j, k^{0}}}, \Phi\left(\widehat{S_{j, k^{o}}}=1\right)\right\}_{t}-\left\{\widehat{P_{j, k^{k}}^{k}}, \widehat{P_{k}^{j, k^{o}}}, \widehat{T_{j, k^{o}}}, \Phi\left(\widehat{S_{j, k^{o}}}=1\right)\right\}_{t-1}\right\|<\eta \forall j \in J, k \in K, k^{o} \in K$,

where $\eta \rightarrow 0$.

\section{Results}

The parameter estimates are presented in Tables 3 and 4 . Table 3 contains the parameters for the cost function in the teacher's initial decision on whether to enter the teacher transfer market. Compared to the base-line case of a teacher with high experience, no advanced degree, and no certification, a teacher is more likely to enter the market if she is less experienced, has an advanced degree, or is certificated, all else equal. This provides confirmation of results found in other studies that show that teachers with high pre-service qualification tend to apply for transfers at a higher rate. Interestingly, currently being at a bad school is not a significant predictor of search.

Mid level experience (4 to 10 years in the teaching profession) is the strongest predictor of search. This is most likely due to the combination of the teacher having earned tenure (thus being more confident about their career prospects compared to low experience teachers) yet young enough to be mobile compared to teachers with more years of service.

Table 4 shows the utility parameters of teachers matching with a particular school type and of schools matching with a particular teacher type. The top-third of Table 4 contains parameters for teacher utility. The parameter on low experience for matching with a bad school type is 0.3224 . That is, compared to the base case of a teacher with high experience originating from a good school, a low experience teacher is happier matching with a bad school. The negative parameter on mid experience can be interpreted as the significant disutility felt by a mid experience teacher when matching with a bad school,

Table 3 Teacher decision to enter transfer market

\begin{tabular}{ll}
\hline & Entry cost parameters (Std. err.) \\
\hline White & $0.1180(0.0217)$ \\
Low exp. & $-0.1608(0.0223)$ \\
Mid exp. & $-0.6661(0.0183)$ \\
MA or above & $-0.1473(0.0173)$ \\
Certified & $-0.1031(0.0257)$ \\
Bad schl. & $-0.0209(0.0226)$ \\
Constant & $1.4472(0.0237)$ \\
\hline
\end{tabular}

Dependent variable is whether the surveyed teacher answered that she would be seeking to move to a new school in the next academic year from the WCS data set. 


\section{Table 4 Teacher-school match}

\begin{tabular}{|c|c|c|c|c|c|c|}
\hline \multicolumn{7}{|c|}{ Teacher side parameters (Std. err.) } \\
\hline & \multicolumn{2}{|c|}{ School types } & & & & \\
\hline & Bad & Good & & & & \\
\hline Low exp. & $0.3224(0.0114)$ & $0.2764(0.0083)$ & & & & \\
\hline Mid exp. & $-0.7503(0.0275)$ & $0.0505(0.0065)$ & & & & \\
\hline$k^{0}=$ bad & $1.4381(0.1279)$ & $0.7085(0.0662)$ & & & & \\
\hline \multirow[t]{4}{*}{ Constant } & $-0.4545(0.0720)$ & $1.3501(0.0013)$ & & & & \\
\hline & \multicolumn{6}{|c|}{ School side parameters (Std. err.) } \\
\hline & \multicolumn{6}{|c|}{ Teacher types (exp. level/origin schl. type) } \\
\hline & Low/bad & Mid/bad & High/bad & Low/good & Mid/good & High/good \\
\hline Bad schl. & $0.8401(0.0127)$ & $1.1031(0.0023)$ & $1.4815(0.0118)$ & $-1.3037(0.0327)$ & $-0.8071(0.0082)$ & $-1.4123(0.0291)$ \\
\hline \multirow[t]{2}{*}{ Constant } & $-2.4802(0.0356)$ & $-1.0205(0.0148)$ & $-0.6287(0.0441)$ & $0.7554(0.0122)$ & $1.6317(0.0531)$ & $2.1385(0.0262)$ \\
\hline & & & Probability parar & & & \\
\hline A & $0.4626(0.0013)$ & & & & & \\
\hline$\alpha$ & 0.5 (fixed) & & & & & \\
\hline
\end{tabular}

Teacher and school utility parameters and matching function estimates. $\alpha$, the matching elasticity from the teacher side, is fixed at 0.5 . 
compared to a highly experienced teacher. This may be due to the fact that a mid-career teacher regards a transfer as a chance to move into a more desirable school, while a highly experienced teacher moving may be driven by life-style concerns unrelated to school quality. The parameter on originating from a bad school is 1.4381 . That is, a teacher from a bad school will be significantly happier to match with a bad school compared to a teacher from a good school.

On the school side (the middle of Table 4), a bad school does not mind matching with a teacher originally from a bad school (0.8401 for low expereince, 1.1031 for mid experience, and 1.4815 for high experience). On the other hand, good schools are significantly happier to match with teachers who originate from good schools. This can be seen by noting that the utility of a good school matching with a low experience teacher from a good school (0.7554) is much higher than the utility of a good school matching with a high experience teacher from a bad school (-0.6287). This shows that good and bad schools have different priorities in recruiting teachers, with bad schools favoring experience and good schools choosing based on where the teacher came from. This will be reflected in the match and search probabilities.

The bottom-third of Table 4 shows the matching parameters. As stated previously, $\alpha$ is fixed in the estimation at 0.5. This has the effect of assuming that teachers and schools contribute equally to the matching process. The number of matches between teachers and schools is now defined as:

$$
\begin{aligned}
X_{\left\{j, k^{o}-k\right\}} & =A\left(\gamma_{j, k^{o}}^{k} T_{j, k^{o}}\right)^{\alpha}\left(\gamma_{k}^{j, k^{o}} O_{k}\right)^{1-\alpha} \\
& =A \sqrt{\gamma_{j, k^{o}}^{k} T_{j, k^{o}} \cdot \gamma_{k}^{j, k^{o}} O_{k}}
\end{aligned}
$$

This is admittedly a strong assumption. Some teachers (or principals) may be more or less active or effective in searching for a match. A more active teacher may skew $\alpha$ higher, and a more active principal may lead to a lower $\alpha$. The probability normalizing constant $A$ was estimated as an exponential function to prevent generating a negative probability ${ }^{30}$.

Table 4 presents the estimated search $\left(\gamma_{j, k^{o}}^{k}\right)$ and match probabilities $\left(P_{j, k^{o}}^{k}\right)$ of teachers. The first two columns present the estimated probability of a $j, k^{0}$-type teacher searching for a $k$-type school. The last two columns show, conditional on searching for a $k$-type school, the estimated probability of the $j, k^{0}$-type teacher matching with the desired school type. For example, $11.18 \%$ of teachers with low experience who are currently at bad schools will seek a match with another bad school, while $88.82 \%$ of these teachers will seek a match with a good school. Of these teachers who search for a bad school, 53.61\% will successfully match. Of these teachers that search for a good school, only $34.73 \%$ will be able to move next year.

Results show that the probability of matching with a bad school is always greater than the probability of matching with a good school for teachers originating from bad schools. This is not very surprising. It is attributable to higher rates of transfer at bad schools, leading to more vacancies, and fewer teachers of all types searching for positions at bad schools, leading to less competition for these positions. Table 4 also shows that the probability of finding a match increases with experience level and with originating from a good school. For matching with a good school, originating from a good school dominates experience level. To match with a bad school, higher experience dominates school origin. 
These probabilities confirm the utility parameter results observed in Table 4, that good and bad schools have different priorities in recruiting teachers.

These match probabilities, along with the utility of matching, drive the search decision of teachers. Most teachers favor searching for a match with a good school. The lack of a flexible wage in the teacher labor market results in bad schools having a difficult time competing with good schools for these teachers. This holds even for teachers with low levels of experience because if a teacher does not succeed in finding a match, she can always take her outside option of remaining at her current school. This emboldens low experience teachers to search at a high rate. Interestingly, low-experienced teachers from good schools have a higher probability of searching for a bad school to match with, compared to all other groups (36\% compared to about $12 \%$ ). This could indicate these teachers who are already in good schools are looking to move for non-occupation-related reasons, or these could be non-tenured teachers who are pushed out of their initial placement after being found to be unsatisfactory ${ }^{31}$.

Table 4 also reconciles why currently being at a bad school does not induce stronger search, as observed in Table 3, yet summary statistics from Table 1 suggests teachers queue for a chance at moving to better schools. While teachers with low and high levels of experience are relatively immobile, mid experience teachers engage in search by focusing almost entirely on matching with good schools. Low experience teachers are immobile because they are more likely to fail to match with their desired school. High experience teachers do not move because they are less likely to be in the transfer market to start. Therefore, while the levels of low and high experienced teachers tend to stay relatively constant across good and bad schools, mid-level experience teachers move aggressively into good schools (or fail to match and stay at the current schools), thus generating the observed aggregate trends.

The probabilities in Table 4 also highlight the turbulence and friction in the teacher labor market that is hidden in the summary statistics. While, as noted above, there are usually large differences in probability of matching to a good school compared to a bad school, even at its largest, the disparity is under 30 percentage points. Low experience teachers from bad schools, who by far are the least likely to succeed in matching with a good school, still have a 35\% chance. High experience teachers from good schools, who have the highest probability of matching with bad or good schools, have a $65 \%$ and a $64 \%$ chance, respectively, meaning even these teachers are not assured of successfully matching with their desired choice all the time. Combined with search probability values, these numbers indicate that there is a lot of movement from good schools to bad schools, from bad to good, from bad to bad, from good to good, and stationary teachers who want to move but fail to find a suitable match. The gradual convergence seen in the data summaries is the result of the combination of all of these movements (as well as teachers who are not searching).

Table 5 presents the search $\left(\gamma_{k}^{j, k^{o}}\right)$ and match probabilities $\left(P_{k}^{j, k^{o}}\right)$ of schools. The top two rows present the estimated probability of a $k$-type school searching for a $j, k^{o}$-type teacher. The bottom two rows show the estimated probability of the $k$-type school successfully matching with the desired $j, k^{0}$-type teacher, conditional on searching for her type. For example, only $3.31 \%$ of bad schools will search for a teacher with low experience who is currently at a bad school. Meanwhile, $35.99 \%$ of these schools will search for a teacher who is already at a good school with a mid-level of experience. 
Table 5 Search/Match probabilities (teacher side): $\gamma_{j, k^{o}}^{k}$ and $P_{j, k^{o}}^{k}$

\begin{tabular}{lccccc}
\hline Tch. Type $\left(\boldsymbol{j}, \boldsymbol{k}^{\boldsymbol{o}}\right)$ & \multicolumn{2}{c}{ Search probabilities $\left(\boldsymbol{\gamma}_{\boldsymbol{j}, \mathbf{k}^{\mathbf{o}}}^{\boldsymbol{k}}\right)$} & & \multicolumn{2}{c}{ Match probabilities $\left(\boldsymbol{P}_{\left.\boldsymbol{j}, \mathbf{k}^{\mathbf{o}}\right)}\right.$} \\
\cline { 2 - 3 } & Bad schl. & Good schl. & & Bad schl. & Good schl. \\
\hline Low exp., bad schl. & 0.1118 & 0.8882 & & 0.5361 & 0.3473 \\
Mid exp., bad schl. & 0.1239 & 0.8761 & & 0.7013 & 0.4683 \\
High exp., bad schl. & 0.1133 & 0.8867 & & 0.7946 & 0.4915 \\
Low exp., good schl. & 0.3664 & 0.6636 & & 0.3875 & 0.6062 \\
Mid exp., good schl. & 0.1892 & 0.8108 & & 0.5520 & 0.6153 \\
High exp., good schl. & 0.0669 & 0.9331 & & 0.6503 & 0.6425 \\
\hline
\end{tabular}

Estimated probability of a $\boldsymbol{j}, \boldsymbol{k}^{\boldsymbol{o}}$-type teacher searching for a $\boldsymbol{k}$-type school $\left(\gamma_{j, k^{o}}^{k}\right)$, and conditional on searching for a $k$-type school, estimated probability of matching $\left(P_{j, k^{o}}^{k}\right)$.

Bad schools have the highest probabilities of matching with teachers with low levels of experience (39.91\% with teachers from bad schools and $55.21 \%$ with teachers from good schools). They also stand a good chance of matching with teachers from good schools, especially those with low levels of experience. This is consistent with the high search rate of these teachers for bad schools, as was seen in Table 4. In addition, because teachers from good schools outnumber those from bad schools by more than 6 to 1 , even a small fraction of teachers from good schools seeking to move to a bad school will make matching relatively easy from the school-side. Good schools can more easily match with teachers from bad schools, but they spend almost no time searching in these markets. Summing across all experience levels, good schools spend only $11.69 \%$ of their search time for teachers from bad schools. Yet even if good schools search in the low experience, bad school origin market, their chance of matching stands at $62 \%$. Again, this is indicative of the high degree of search friction in the teacher transfer labor market. These probabilities affect the schools' search decisions. Bad schools search mostly for mid-level and highly experienced teachers originating from both bad and good schools (77.03\% of their search time). Good schools focus mostly on mid-level and highly experienced teachers from good schools (75.06\% of their search time). Again, this confirms the utility parameters on the school side from Table 4.

The motivation for bad schools in focusing their search on teachers with mid experience from good schools is more complex. From Table 6, we see that the probability of a bad school matching with teachers from good schools is surprisingly high, at almost $40 \%$ for mid-experience teachers. This is because there are so many teachers from good schools

Table 6 Search/Match probabilities (school side): $\gamma_{k}^{j, k^{o}}$ and $P_{k}^{j, k^{o}}$

\begin{tabular}{|c|c|c|c|c|c|c|}
\hline \multirow[t]{2}{*}{ School type (k) } & \multicolumn{6}{|c|}{ Search probabilities $\left(\gamma_{k}^{j, k^{o}}\right)$} \\
\hline & Low, bad & Mid, bad & High, bad & Low, good & Mid, good & High, good \\
\hline Bad schl. & 0.0331 & 0.0853 & 0.1191 & 0.1967 & 0.3599 & 0.2060 \\
\hline \multirow[t]{3}{*}{ Good schl. } & 0.0175 & 0.0427 & 0.0567 & 0.1325 & 0.3050 & 0.4456 \\
\hline & \multicolumn{6}{|c|}{ Match probabilities $\left(P_{k}^{j, k^{o}}\right)$} \\
\hline & Low, bad & Mid, bad & High, bad & Low, good & Mid, good & High, good \\
\hline Bad schl. & 0.3991 & 0.3050 & 0.2692 & 0.5521 & 0.3876 & 0.3290 \\
\hline Good schl. & 0.6161 & 0.4568 & 0.4353 & 0.3529 & 0.3477 & 0.3329 \\
\hline
\end{tabular}

Estimated probability of a $k$-type school searching for a $\boldsymbol{j}, \boldsymbol{k}^{\boldsymbol{o}}$-type teacher $\left(\gamma_{\boldsymbol{k}}^{j, \boldsymbol{k}^{\boldsymbol{o}}}\right)$, and conditional on searching for a $\boldsymbol{j}, \boldsymbol{k}^{\boldsymbol{o}}$-type teacher, estimated probability of matching $\left(\boldsymbol{P}_{\boldsymbol{k}}^{j, \boldsymbol{k}^{\boldsymbol{o}}}\right)$. 
in the transfer market. As over $85 \%$ of schools in North Carolina are designated as good schools, even a small fraction of these teachers choosing to search for a match with bad schools greatly increase these schools' likelihoods of finding their desired matches.

In addition, the search patterns of schools reveals the true value of the outside option, new teachers. Schools are weighing two options. $P$ is the probability of matching, and $\mu$ (exp.) is the school's utility of matching with a teacher with low, high, or no experience.

$$
(\text { low } P) \cdot \mu(\text { high exp. })-\mu(\text { no exp.) }
$$

and

$$
(\text { high } P) \cdot \mu(\text { low exp. })-\mu(\text { no exp.) }
$$

The top equation is the difference in expected utility from searching for a highly experienced teacher and the outside option (new teacher). The bottom equation is the difference in expected utility of matching with a low experience teacher and the outside option. By the observed search behavior of schools, it is clear that both good and bad schools find the top value to be greater than the bottom. This can be true due to a combination of three reasons: a) small difference in P, b) large difference between $\mu$ for high and low experienced teachers, and c) a high $\mu$ value for new teachers. Since Table 5 shows that the probability difference is relatively large, and from the literature it is known that the productivity difference between high and low experienced teachers is rather small, it must be that $\mu$ (no exp.) is high enough to make new teachers a viable substitute for low experienced teachers ${ }^{32}$. The relatively high likelihood of matching with experienced teachers and the ready substitute in the form of new teachers induces bad schools to be ambitious in courting experienced teachers from good schools.

\section{Policy Simulations}

In the previous section, I showed the teacher transfer market, while looking placid and orderly on the surface, is actually very turbulent and active. Therefore, attempting to intervene to redirect teacher transfers without accounting for the two-sided targeted search and friction may have unintended consequences.

An example of an actual policy change attempted at the district level (CharlotteMecklenburg, North Carolina) included a complete ban on teachers transferring to schools that had met district goals for average teacher experience and fraction of teachers holding advanced degrees. The district concurrently offered incentives to encourage teacher transfers into high poverty schools.

In an attempt to explore the policy implications of trying to increase teacher quality at disadvantaged schools, I run two simulations that change the number of vacancies and estimated utility parameter values to generate new counts of searching teachers and schools and new probabilities of searching and matching.

The first simulation shuts down transfers into a fraction of vacancies in good schools by decreasing the number of positions potentially available by 15 percent, essentially setting the probability of these schools searching for teachers across all markets to zero. Charlotte-Mecklenburg is the largest school district in North Carolina, and roughly $1 / 8$ of teaching positions in the sample are located in this district. This simulation approximates the impact on teachers state-wide of banning transfers into Charlotte-Mecklenburg 
schools that had already met their goals for recruiting teachers with good observable characteristics. The simulation results are presented in Table 7 .

The left-side of the table shows the probability of teachers entering the market, the search probabilities, and the match probabilities conditional on entering the market. The column labeled ' $N$ ' shows the number of teachers of each experience level $(j)$ ending up (whether through matching, failing to match, or not searching) in school type $(k)$. The right-side of the table contrasts the simulation results with the estimated probabilities and equilibrium distribution of teachers from the base case.

With the reduction in positions available for matching, teacher entry into transfer market decreases for every type except those with low experience from good schools. The decline is especially steep for low and high experience teachers from bad schools, who are less likely to engage in search by 8.4 and 7.1 percentage points, respectively. This change is due to the direct effect of teachers who were considering searching in the good school market pulling back, as well as the indirect effect of a reduction in match probability across the board from teachers generally redistributing their search effort toward bad schools.

Search probability $\left(\gamma_{j, k^{o}}^{k}\right)$ uniformly shifts toward bad schools. This is especially pronounced for low experience teachers from good schools, who shift search by 10 percentage points. From the school-side, a reduction in the number of vacancies from good schools means lower competition for highly desirable teachers for good schools that are still in the market. As such, their strategy of search shifts to searching more heavily for mid and high experience teachers from good schools. Low experience teachers from good schools who are in the search market respond to this by shifting search to the bad school market, where they are most likely to find a match.

Simulation results show fairly substantial decreases in match probability $\left(P_{j, k^{o}}^{k}\right)$ across all teacher types for bad schools. Match probabilities in good schools, interestingly, increase slightly or are flat across all teacher types. This change is driven by the shift in search strategy of low experience teachers from good schools, who make up a sizable fraction of teachers in the data. Because these teachers shift away from the good school market, other teachers who decide to search in the good school market benefit from decreased competition.

Examining the equilibrium distribution of teachers after the policy implementation, we see that the policy yielded mixed results. The number of teachers in bad schools with low and high experience rose by $8.1 \%$ and $2.9 \%$, respectively, while the number of mid experience teachers actually fell by $0.7 \%$. The largest changes in movement patterns for teachers compared to the base case were large numbers of low experience teachers in good schools switching to bad schools and most teachers becoming less likely to enter the transfer market. While the broad suppression of search may be what policy makers intended, examining the distribution of teachers after the simulation, it is far from clear that bad schools benefit from this policy. As described above, schools reveal themselves to regard low experience and new teachers about equally. This valuation gives bad schools license to take chances in recruiting more highly experienced teachers. Bad schools, therefore, may be indifferent to a policy where the primary impact is changing one set of teachers (those with low experience) for an identically valuable set of other teachers (those with no experience). 
Table 7 Policy simulation results with vacancies at good schools reduced by $15 \%$

\begin{tabular}{|c|c|c|c|c|c|c|c|c|c|c|c|c|}
\hline \multicolumn{7}{|c|}{ Simulation results } & \multicolumn{6}{|c|}{ Differences (Simulation results - base case) } \\
\hline & \multirow[t]{2}{*}{ Mkt entry } & \multicolumn{2}{|c|}{ Search Pr. $\left(\gamma_{j, k^{o}}^{k}\right)$} & \multicolumn{2}{|c|}{$\operatorname{Match} \operatorname{Pr} .\left(P_{j, k^{o}}^{k}\right)$} & \multirow[t]{2}{*}{$\mathbf{N}$} & \multirow[t]{2}{*}{$\Delta$ Mkt entry } & \multicolumn{2}{|c|}{$\Delta \gamma_{j, k^{o}}^{k}$} & \multicolumn{2}{|c|}{$\Delta P_{j, k^{o}}^{k}$} & \multirow[t]{2}{*}{$\Delta \% \mathrm{~N}$} \\
\hline & & Bad sch & Good sch & Bad sch & Good sch & & & Bad sch & Good sch & Bad sch & Good sch & \\
\hline Low/bad & 0.396 & 0.166 & 0.834 & 0.483 & 0.353 & 537.7 & -0.084 & 0.055 & -0.055 & -0.053 & 0.005 & 0.081 \\
\hline Mid/bad & 0.437 & 0.181 & 0.820 & 0.656 & 0.486 & 662.8 & -0.007 & 0.057 & -0.057 & -0.045 & 0.017 & -0.007 \\
\hline High/bad & 0.259 & 0.140 & 0.860 & 0.779 & 0.512 & 443.8 & -0.071 & 0.027 & -0.027 & -0.016 & 0.021 & 0.029 \\
\hline Low/good & 0.341 & 0.466 & 0.534 & 0.370 & 0.617 & 2225.3 & 0.006 & 0.100 & -0.100 & -0.018 & 0.010 & -0.028 \\
\hline Mid/good & 0.289 & 0.207 & 0.793 & 0.527 & 0.610 & 3840.2 & -0.039 & 0.018 & -0.018 & -0.025 & -0.005 & 0.001 \\
\hline High/good & 0.213 & 0.070 & 0.930 & 0.630 & 0.636 & 3686.2 & -0.011 & 0.003 & -0.003 & -0.020 & -0.007 & -0.003 \\
\hline
\end{tabular}

'Mkt Entry' is the likelihood of a teacher type $\boldsymbol{j}, \boldsymbol{k}^{\boldsymbol{o}}$ deciding to enter the transfer market. 'Search Pr. $\left(\gamma_{j, k^{0}}^{k}\right)^{\prime}$ is the directed search probabilities of a representative teacher of type $\boldsymbol{j}, \boldsymbol{k}^{\boldsymbol{o}}$ toward a school type $k$, conditional on deciding the enter the transfer market. 'Match $\operatorname{Pr} .\left(P_{j, k^{o}}^{k}\right)$ is the probability of a teacher of type $\boldsymbol{j}, \boldsymbol{k}^{\boldsymbol{o}}$ successfully matching with a school type $k$, conditional on searching in that market. 
The second simulation explicitly increased the utility that a mid experience teacher receives from matching with a bad school. The number of 'utils' for a mid experience teacher from a bad school matching with another bad school is approximately 0.23 . The same teacher's utility in matching with a good school is approximately 2.12. I increase the parameter for mid experience in the utility of matching with a bad school by .375 , which decreases the utility gap between these two types of schools by about $20 \%$. This simulation approximates the impact of offering incentives to encourage mid-career teachers to move to schools that had been difficult to staff. While the choice of $20 \%$ is somewhat arbitrary, policy makers do seem to be aware that small improvements in bad schools will not induce teachers to locate to (or remain at) these schools. A teacher in North Carolina with a bachelor's degree, certification, and 10 years of experience would earn just over $\$ 40,000$ (2006 dollars) in $2006^{33}$. In addition to bonuses available to teachers state-wide from year-over-year standardized test score gains, teachers were eligible to receive additional monetary compensation for signing up to teach in a bad school, a recruitment "signing" bonus (for the person who recruited the new teacher), an annual retention incentive for teachers with more experience and advanced degrees, and an additional pilot payfor-performance program specifically aimed at schools in Charlotte-Mecklenburg that underperformed. Altogether, available bonuses in these poor schools may total as much as $\$ 8,500^{34}$. Perhaps just as important, the federal No Child Left Behind (NCLB) act and local initiatives began to push for recruiting better leadership (through pay-incentives) and even forcibly replacing bad leadership at under-performing schools. Upgrading leadership at these schools should substantially raise the utility of teachers. Teachers cite good leadership as one of the most important factors that determine whether a school is a desirable place to work, and better leadership leads to higher academic performance (Ahn and Vigdor 2014) ${ }^{35}$. Results from the policy simulation are presented in Table 8.

When bad schools are made more attractive, market entry patterns change predictably. More mid experience teachers from good schools enter the transfer market. Just as importantly, this suppresses search of mid experience teachers from bad schools by more than 10 percentage points. These large changes in mid experience teachers' propensity to search has ripple effects for other types of teachers. The focused attention on bad schools leads to a reduction in the likelihood of entry into the transfer market of low and high experienced teachers from bad schools. In contrast, low and high experienced teachers from good schools are induced to search more.

For search probability $\left(\gamma_{j, k^{\circ}}^{k}\right)$, mid experience teachers from both bad and good schools shift heavily toward searching in the bad schools market, by 7.5 and 2.1 percentage points, respectively. Interestingly, all other types of teachers shift search to bad schools as well, with the exception of high experience teachers from good schools.

This large increase in search in the bad school market predictably leads to lower match probabilities for low and mid experience teachers in these markets. Due to the increased search in bad schools, teachers of all types find greater chances of success in matching with a good school. For example, mid experience teachers from bad schools are less likely to be successful moving laterally by 3 percentage points but are more likely to be successful moving to a good school by 4.8 percentage points.

The equilibrium distribution of teachers after this policy simulation yields modestly favorable results. In particular, the number of mid and high experience teachers at bad schools increases by $6.6 \%$ and $1.4 \%$, respectively. Interestingly, low experience teachers at 
Table 8 Policy simulation results with utility of mid-experience teachers at bad schools increased by $20 \%$

\begin{tabular}{|c|c|c|c|c|c|c|c|c|c|c|c|c|}
\hline \multicolumn{7}{|c|}{ Simulation results } & \multicolumn{6}{|c|}{ Differences (Simulation results - base case) } \\
\hline & \multirow[t]{2}{*}{ Mkt Entry } & \multicolumn{2}{|c|}{ Search Pr. $\left(\gamma_{j, k^{o}}^{k}\right)$} & \multicolumn{2}{|c|}{ Match Pr. $\left(P_{j, k^{o}}^{k}\right)$} & \multirow[t]{2}{*}{$\mathbf{N}$} & \multirow[t]{2}{*}{$\Delta$ Mkt Entry } & \multicolumn{2}{|c|}{$\Delta \gamma_{j, k^{o}}^{k}$} & \multicolumn{2}{|c|}{$\Delta P_{j, k^{o}}^{k}$} & \multirow[t]{2}{*}{$\Delta \% \mathrm{~N}$} \\
\hline & & Bad sch & Good sch & Bad sch & Good sch & & & Bad sch & Good sch & Bad sch & Good sch & \\
\hline Low/bad & 0.444 & 0.185 & 0.815 & 0.484 & 0.370 & 524.7 & -0.037 & 0.073 & -0.073 & -0.052 & 0.023 & 0.055 \\
\hline Mid/bad & 0.341 & 0.199 & 0.801 & 0.670 & 0.517 & 711.7 & -0.103 & 0.075 & -0.075 & -0.031 & 0.048 & 0.066 \\
\hline High/bad & 0.257 & 0.131 & 0.869 & 0.803 & 0.529 & 437.5 & -0.073 & 0.018 & -0.018 & 0.009 & 0.038 & 0.014 \\
\hline Low/good & 0.357 & 0.433 & 0.567 & 0.366 & 0.626 & 2238.3 & 0.022 & 0.067 & -0.067 & -0.022 & 0.020 & -0.022 \\
\hline Mid/good & 0.341 & 0.210 & 0.790 & 0.542 & 0.633 & 3791.3 & 0.013 & 0.021 & -0.021 & -0.011 & 0.018 & -0.012 \\
\hline High/good & 0.239 & 0.050 & 0.950 & 0.683 & 0.648 & 3692.5 & 0.015 & -0.017 & 0.017 & 0.033 & 0.005 & -0.002 \\
\hline
\end{tabular}

'Mkt Entry' is the likelihood of a teacher type $\boldsymbol{j}, \boldsymbol{k}^{\boldsymbol{o}}$ deciding to enter the transfer market. 'Search Pr. $\left(\gamma_{j, k^{0}}^{k}\right)^{\prime}$ is the directed search probabilities of a representative teacher of type $\boldsymbol{j}, \boldsymbol{k}^{\boldsymbol{o}}$ toward a school type $\boldsymbol{k}$, conditional on deciding the enter the transfer market. 'Match Pr. $\left(P_{j, k^{o}}^{k}\right)$ is the probability of a teacher of type $j, \boldsymbol{k}^{o}$ successfully matching with a school type $k$, conditional on searching in that market. 
these schools increase by $5.5 \%$ as well. The unfilled vacancies at good schools are now filled by newly minted teachers. Overall, increasing the desirability of bad schools seems to be effective in moving and keeping experienced teachers to these schools. However, a rough estimate of the cost of implementing such a policy state-wide shows that it would most likely be prohibitively expensive. If we assume that teachers with 4 or more years of experience would have to be offered an additional $\$ 8,000$ to achieve these gains for bad schools, this would cost the state of North Carolina approximately $\$ 65$ million per year ${ }^{36}$. As a comparison, the North Carolina state-wide pay-for-performance accountability system had an annual price tag of roughly $\$ 80$ million. It was discontinued in 2009 due to funding difficulties despite support for the policy from parents, teachers, and politicians. A policy designed to improve $15 \%$ of public schools, often at the cost of poaching good teachers from other schools, would most likely find wide-spread support lacking.

It must be acknowledged that the results of the simulations are for the short-run, as entry and exit decisions are not a part of the theory model. As such, while it is tempting to push the simulation to consider general equilibrium impacts of more robust, drastic policy changes, the results from such policy simulations will most likely not hold in the long-run, as teachers who are already in the market change their exit decision, and new potential entrants change their behavior (resulting in a change in the number of entrants overall as well as the number of teachers in each school type). I therefore examine a range of policy changes that are not likely to have a large impact on long-term career decisions of current and potential teachers ${ }^{37}$.

\section{Conclusion}

This study explored the decisions teachers and schools make to search for matches, resulting in successful and unsuccessful teacher transfers. A fuller understanding of the transfer market is especially important given the fact that roughly 10 to $20 \%$ of teachers turnover each year, and first impressions of the teacher labor market that emerge from simple summary statistics are misleading. Policies designed to direct teacher transfers toward a more efficient or equitable outcome will have unintended consequences without a more complete picture of the transfer market.

I showed that a teacher's decision to enter the transfer market is driven by the expected utility of matching (across all market types) as well as her professional characteristics. In particular, experience level (between 4 to 10 years), advanced degrees, and certification led to lower entry cost and a higher probability of searching. Better pre-service qualifications leading to more search confirms results from other studies. The high likelihood of mid-career teachers searching indicates that teachers know when they are most desirable to schools and choose to search for a new position before they become entrenched (and moving costs become too high).

Conditional on searching, teachers evaluate the probability of finding a successful match in each market conditional on their type and select their market optimally. Teachers from both bad and good schools focus their search on good schools, with the notable exception of low experience teachers from good schools, who divide their search effort more evenly between good and bad schools. Originating from a good school and having high experience is associated with being able to match with a good school, while a teacher's experience level is crucial in matching with a bad school. Teachers with low 
experience have a distinctly tougher time successfully matching with schools, either good or bad.

Bad schools tend to target medium and highly experienced teachers from both bad and good schools, while good schools search for experienced teachers originating from good schools. The matching rate from the school side is relatively low across all teacher types (with the exclusion of low experienced teachers), hinting at the possibility of a very inefficient market.

Both bad and good schools have relatively high probabilities of matching with low experienced teachers, yet they decide to shun these markets (although bad schools will sometimes search for low experience teachers from good schools). The search pattern of schools in light of the probability of match reveals why both types of schools behave in this manner. Good schools simply focus on recruiting highly experienced teachers from good schools because they have a high probability of finding their desired match. Bad schools are indifferent bewteen low experienced teachers and newly minted teachers. Since the outside option is guaranteed, many of these schools will attempt to match with a teacher with more experience.

One significant characteristic that was not included in the model set up was whether search was within district or across the entire state ${ }^{38}$. Boyd et al. (2002) showed that geographic distance is an important consideration for search on the teacher side. There may also be institutional barriers in place to restrict inter-district hiring. This characteristic was excluded due to computational reasons. Instead of one set of probability of search and match by types, each district would require one set, making calculation intractable. While accounting for intra or inter-district transfer would certainly change the parameter estimates and probabilities, qualitative results are unlikely to chang $\mathrm{e}^{39}$.

Contrary to impressions that one may get from the summary statistics, there exists significant labor market volatility and search friction in the teacher transfer market. It is clear that teachers do not have an orderly, safe march up the quality ladder from bad to good schools as they gain experience. There are significant numbers of teachers at all experience levels that move up to good schools, down to bad schools, or transfer to schools of the same type as their origin. In addition, a significant portion of teachers and schools search for, yet fail to find the right match due to high search friction.

A closer look at the teacher transfers reveals a volatile and complex labor market underneath the placid surface portrayed by the summary statistics. Yet at the same time, the searching behavior of teachers and schools are consistent with those seen in other search markets.

Policy simulations of simple interventions to prevent or slow down the movement of teachers up the quality ladder without taking into account the general equilibrium implications of such government actions proved to be mostly ineffective. Direct intervention to suppress movement of experienced teachers by closing a subset of the good school market induced large increases in the number of relatively inexperienced teachers at bad schools. Making bad schools more desirable does increase the number of experienced teachers at these schools, but this policy carries a very high price tag. This points to the conclusion that simplistic rule changes to redirect transfers will most likely be unsuccessful in increasing efficiency or equity. To get experienced teachers to stay at 'bad' schools, policy makers will have to change the characteristics of these schools that make them so unattractive, which promises to be an expensive endeavor. Ultimately, while the outcome 
of simplistic policy interventions in the teacher transfer market will be, at best, opaque, it is encouraging that insights gained from other matching labor markets will be applicable to this market as well.

\section{Endnotes}

${ }^{1}$ Alternatively, it is possible that teachers are actually sorting themselves into more productive positions (Jackson 2013)

${ }^{2}$ For example, the New Teacher Project. See Levin et al. (2005).

${ }^{3}$ Other examples of structural models in analyzing education issues include Stinebrickner (2001) and van der Klauuw (2012).

${ }^{4}$ The assumption here is that once principals are not bound by the restrictive rule, they will be able to pursue candidates that are the best fit for their school. Some researchers and practitioners have gone further to consider firing of ineffective teachers. See Hanushek (2010) to explore increases in test scores by replacing the worst teacher with an average teacher. Michelle Rhee, former chancellor of the Washington D.C. public school system fired over 200 low-performing teachers during her tenure. Some focus has also been paid to the difficulty of getting rid of particularly ineffective teachers. See Jacob (2010). Recently, a California court case ruled teacher tenure laws deprived students the right to an equitable education, guaranteed under the state Constitution. See Medina (2014).

${ }^{5}$ Some research has looked at response of new teachers to high wage as well as policy experiments aimed at increasing retention through higher pay. See Murnane et al. (1989), Rickman and Parker (1990), and Clotfelter et al. (2008).

${ }^{6}$ Seniority-status may not be portable across school districts.

${ }^{7}$ Monetary rewards are sometimes offered in the form of signing and retention bonuses and recruiting drives for math and science teachers in hard-to-staff areas. See Clotfelter et al. (2008).

${ }^{8}$ The economics literature has focused on identifying characteristics that proxy for teacher quality, finding that experience, education level, and credentials are correlated with higher student achievement (Goldhaber and Anthony 2007 and Rockoff 2004, among many others). Research on accountability legislation such as the No Child Left Behind Act and other state-specific programs have focused on the impact of introducing market pressures to induce teachers and administrators to increase education output. Market pressure may thus lead principals to compete for the 'best' teachers (Ahn 2013).

${ }^{9}$ I remain agnostic about whether teachers themselves collectively impose centralized matching (to benefit senior members, say); however, this appears unlikely. Teachers in $\mathrm{NC}$ are prohibited by law from collectively bargaining with the state or districts (Winkler et al. 2012).

${ }^{10}$ Boyd et al. (2011) has this information on the teacher side explicitly.

${ }^{11}$ See Fox (2010) for an example.

${ }^{12}$ See Arcidiacono et al. (2010) for a similar set up.

${ }^{13}$ If a teacher is indifferent between searching and not searching, I assume, with no loss of generality, that she chooses not to search. Schools are never indifferent between searching and not searching. If a teacher (school) is indifferent across more than one type of school (teacher), search effort is equally distributed across indifferent types. If more than one match results for a particular teacher or school, the match that yields the highest utility for the entity with the multiple matches is observed in the data. If a teacher has multiple matches and one of those matches is with a school that also has multiple matches, the match must be pair-wise stable for it to observed in the data. See Fox (2010) for a definition of pair-wise stability.

${ }^{14}$ Teachers answering that they plan to leave the profession are dropped from the dataset. See section 3.5 for a justification. 
${ }^{15}$ Although I have a wealth of teacher and school characteristics, I use only a subset for estimation purposes for tractability. See the estimation section for more details.

${ }^{16}$ Specifically, low-performing schools are categories: Low Performing and Priority Schools. High-performing schools are categories: No Recognition, Schools of Progress, Schools of Distinction, Schools of Excellence, and Honor Schools of Excellence. For more detailed information about school categorizations, refer to: http://www. ncreportcards.org/src/How2ReadSRC.pdf. From hereon, I label low-performing and high-performing schools as bad and good schools, respectively.

${ }^{17}$ These are also the categories the state chooses to emphasize in school report cards. For more detailed information, refer to: http://www.ncreportcards.org/src/ How2ReadSRC.pdf.

${ }^{18}$ The decision to search in the WCS is self-reported. It is possible that some teachers were merely expressing frustration with their current position rather than a decision to enter the transfer market. Estimating the model assuming only some fraction of declared searchers actually search increases the probability of matching successfully from the teacher-side (At the limit,the matching function becomes min \{teachers, vacancies\} and probability of matching equals 1). Assuming all searching teachers identified in the WCS actively search leads to a transfer success rate of approximately $60 \%$, which is actually higher than success rates reported elsewhere.

${ }^{19} \mathrm{An}$ interesting result of defining the utility and the multinomial logit model in this way is that there is no need to normalize one of the probabilities by setting one set of choice parameters to zero. All that is required is to set one of the $C_{j, k^{o}}^{k}$ to a constant.

${ }^{20}$ If some schools have a preference for new teachers over experienced teachers, this would show up as an overestimation of all search probabilities from the school side in the estimation.

${ }^{21}$ If search cost is actually different across school types, this would be reflected in the search probability. $\gamma$ would now be a combination of the probability of finding a match, conditional on searching for a particular type of teacher, as well as the direct cost differential (compared to searching for a base teacher type).

${ }^{22}$ In the estimation, I normalize $\mu_{k}^{0}=-1$ for all $k$.

${ }^{23}$ I exclude new teachers' entry decision because it makes no sense for 'new' teachers to decide to forgo entry into the labor market.

${ }^{24}$ See Brewer (1996) or Dolton and van der Klauuw (1999).

${ }^{25}$ It is possible that some positions will remain unfilled, especially in poor inner-city schools. In the model, this will mean that the number of vacancies in 'bad' schools is under-counted, resulting in an overestimation of the probability of these schools successfully matching with teachers.

${ }^{26}$ I was unable to use teacher fixed-effects as a characteristic due the inability of assigning fixed-effects values to teachers at the (unconditional) search decision, where it is impossible to directly link these teachers to the administrative data set.

${ }^{27}$ One other reason to use origin school type ('bad' or 'good' school) is for practicality. Because of the need to split searchers in discrete markets, using any other typical school characteristic (\% traditionally disadvantaged group for example) would require an arbitrary cut off value to define markets. School category has the distinction of being a form of segmentation that the state decided was important. In addition, while it is possible to add in more teacher or school characteristics, each new variable geometrically increases the number of markets to search over, greatly complicating the estimation. For example, if a simple teacher minority status was added, this would increase the number of teacher types to twelve. It is impossible to add a continuous characteristic, as that would imply an infinite number of markets with no mass.

${ }^{28}$ If teachers are matched by a central authority according to a seniority rule, the model would express this preference by over-estimating a good school's utility from matching with an experienced teacher. The higher utility would be consistent with more 
good schools choosing to search in the experienced teacher market, which in turn will lead to a higher probability of good teachers successfully matching with good schools.

${ }^{29}$ The elasticity of matching term $\alpha$ is structurally identified. However, estimation allowing the term to float free yielded poor results. This most likely indicates that $\alpha$ may differ by a) teacher and school types and b) characteristics on both sides of the market that cannot be incorporated into the model, such as teacher/principal reputation or effort in conducting the search.

${ }^{30}$ Bounding $A$ above zero conveniently eliminates the need to worry about negative match probabilities $(P)$ yielding a valid search probability $(\gamma)$. As I defined in the model section, $\gamma_{j, k^{o}}^{k}=\frac{\exp \left(\mu_{j, k^{o}}^{k}+\frac{1-P_{j, k^{o}}^{k}}{P_{j, k^{o}}^{k}} \mu_{j, k^{o}}^{k^{o}}-C_{j, k^{o}}^{k}\right)}{\sum_{k^{\prime}} \exp \left(\mu_{j, k^{o}}^{k^{\prime}}+\frac{1-P_{j, k^{o}}^{k^{\prime}}}{P_{j, k^{o}}^{k^{\prime}}} \mu_{j, k^{o}}^{k^{o}}-C_{j, k^{o}}^{k^{\prime}}\right)}$. Negative P's, which are wrapped inside of exponential functions will still lead to positive $\gamma$ 's.

${ }^{31}$ This group of teachers would be the only teachers who may not have the outside option of remaining in their current school.

${ }^{32}$ Another possibility is that many schools are not allowed to recruit from the low experience pool due to collective bargaining agreements.

${ }^{33}$ See http://www.ncpublicschools.org/docs/fbs/finance/salary/schedules/200607schedules.pdf for table of salaries used in the author's calculation.

${ }^{34}$ See http://cpre.wceruw.org/conference/nov04/cms04.pdf for the list and descriptions of state and district specific bonus programs.

${ }^{35}$ Step-by-step instructions for both policy simulations are in the appendix.

${ }^{36}$ Assume that $15 \%$ of schools are designated as bad, $75 \%$ of teachers have $4+$ years of experience, and there are approximately 80,000 full-time public school teachers in the state.

${ }^{37}$ It is also unlikely that drastic policies will have the political support to be implemented.

${ }^{38} \mathrm{~A}$ strict interpretation of the model would mean that teachers and schools are searching across the entire state.

${ }^{39}$ Estimation using a restricted sample (one large district: Charlotte-Mecklenburg) looking at only within-district transfers yielded qualitatively similar results.

\section{Appendix}

\section{Identification}

Looking at the estimation, it is initially strange to note that there is no 'excluded' category for the discrete choice model. For instance, teachers, conditional on searching, are really making a binary choice between good and bad schools, yet there is a set of parameter estimates for good school choice and bad school choice. The reasoning for this is as follows.

Note that usually, we have an excluded category because of an indeterminacy problem in identifying the probabilities. That is, when we have a simple linear utility function of individual $i$ for choice $k$, we usually have:

$$
\operatorname{Pr}\left(Y_{i}=k \mid x_{i}\right)=\frac{\exp \left(x_{i}^{\prime} \beta_{k}\right)}{\sum_{k=0}^{K} \exp \left(x_{i}^{\prime} \beta_{k}\right)}
$$

Then, defining any $\beta_{k}^{*}=\beta_{k}+\alpha$ for any $\alpha$ leads to the same probabilities, as:

$$
\operatorname{Pr}\left(Y_{i}=k \mid x_{i}\right)=\frac{\exp \left(x_{i}^{\prime}\left(\beta_{k}+\alpha\right)\right)}{\sum_{k=0}^{K} \exp \left(x_{i}^{\prime}\left(\beta_{k}+\alpha\right)\right.}=\frac{\exp \left(x_{i}^{\prime} \beta_{k}\right) \exp \left(x_{i}^{\prime} \alpha\right)}{\sum_{k=0}^{K} \exp \left(x_{i}^{\prime} \beta_{k}\right) \exp \left(x_{i}^{\prime} \alpha\right)}=\frac{\exp \left(x_{i}^{\prime} \beta_{k}\right)}{\sum_{k=0}^{K} \exp \left(x_{i}^{\prime} \beta_{k}\right)}
$$


Therefore, the convention is to set one of the choice specific parameters to zero, such that:

$$
\operatorname{Pr}\left(Y_{i}=k \mid x_{i}\right)=\frac{\exp \left(x_{i}^{\prime} \beta_{k}\right)}{1+\sum_{k=1}^{K} \exp \left(x_{i}^{\prime} \beta_{k}\right)}
$$

However, note that in this model, I have an additional set of terms that enter that are choice-specific that must be determined simultaneously with $\beta_{k^{o}}$. Namely, the probability of matching with a type of school. The (simplified) probability is:

$$
\operatorname{Pr}\left(Y_{i}=k \mid x_{i}\right)=\frac{\exp \left(x_{i}^{\prime} \beta_{k}+\frac{1-P_{i}^{k}}{P_{i}^{k}} x_{i}^{\prime} \beta_{k^{o}}\right)}{\sum_{k=0}^{K} \exp \left(x_{i}^{\prime} \beta_{k}+\frac{1-P_{i}^{k}}{P_{i}^{k}} x_{i}^{\prime} \beta_{k^{o}}\right)}
$$

Applying the same logic as above, we have:

$$
\operatorname{Pr}\left(Y_{i}=k \mid x_{i}\right)=\frac{\exp \left(\left(x_{i}^{\prime}\left(\beta_{k}+\alpha\right)+\frac{1-P_{i}^{k}}{P_{i}^{k}} x_{i}^{\prime}\left(\beta_{k^{o}}+\alpha\right)\right)\right.}{\sum_{k=0}^{K} \exp \left(\left(x_{i}^{\prime}\left(\beta_{k}+\alpha\right)+\frac{1-P_{i}^{k}}{P_{i}^{k}} x_{i}^{\prime}\left(\beta_{k^{o}}+\alpha\right)\right)\right.}
$$

Since the vector of $\beta^{*}$ is now:

$$
\beta^{*}=\left[\beta_{j}+\alpha, \frac{1-P_{i}^{k}}{P_{i}^{k}} \beta_{k^{o}}+\frac{1-P_{i}^{k}}{P_{i}^{k}} \alpha\right]
$$

The $\alpha$ cannot be eliminated from the expression. Therefore, the probabilities are uniquely identified without the usual zero restriction. Note that this is actually a necessity in my model, as I need to predict the matching probabilities of all categories.

\section{Explicit Derivation of Identification}

For teachers, to simplify, there is only good (G) and bad (B) schools, and low experience $(\mathrm{L})$ and high experience $(\mathrm{H})$ teachers. Then:

$$
\begin{aligned}
& E\left(U_{L, B}^{G}\right) / P_{L, B}^{G}=\mu_{L, B}^{G}+\frac{1-P_{L, B}^{G}}{P_{L, B}^{G}} \mu_{L, B}^{B}+\epsilon_{L, B}^{G} \\
& E\left(U_{L, B}^{B}\right) / P_{L, B}^{B}=\frac{1}{P_{L, B}^{B}} \mu_{L, B}^{B}+\epsilon_{L, B}^{B}
\end{aligned}
$$

With the second term as the anchor, we can write:

$$
\begin{aligned}
P(G \mid L, B) & =\frac{\exp \left(\mu_{L, B}^{G}+\left(\frac{1-P_{L, B}^{G}}{P_{L, B}^{G}}-\frac{1}{P_{L, B}^{B}}\right) \mu_{L, B}^{B}\right)}{1+\exp \left(\mu_{L, B}^{G}+\left(\frac{1-P_{L, B}^{G}}{P_{L, B}^{G}}-\frac{1}{P_{L, B}^{B}}\right) \mu_{L, B}^{B}\right)} \\
P(B \mid L, B) & =1-P(G \mid L, B)=\frac{1}{1+\exp \left(\mu_{L, B}^{G}+\left(\frac{1-P_{L, B}^{G}}{P_{L, B}^{G}}-\frac{1}{P_{L, B}^{B}}\right) \mu_{L, B}^{B}\right)}
\end{aligned}
$$

Therefore, all terms are identified. Similar logic follows for teachers of type $(L, G)$, $(H, B)$, and $(H, G)$. 
For schools, we have:

$$
\begin{aligned}
E\left(U_{G}^{L, B}\right) / P_{G}^{L, B} & =\mu_{G}^{L, B}+\frac{1-P_{G}^{L, B}}{P_{G}^{L, B}} \mu_{G}^{o}+\epsilon_{G}^{L, B} \\
E\left(U_{G}^{L, G}\right) / P_{G}^{L, G} & =\mu_{G}^{L, G}+\frac{1-P_{G}^{L, G}}{P_{G}^{L, G}} \mu_{G}^{o}+\epsilon_{G}^{L, G} \\
E\left(U_{G}^{H, B}\right) / P_{G}^{H, B} & =\mu_{G}^{H, B}+\frac{1-P_{G}^{H, B}}{P_{G}^{H, B}} \mu_{G}^{o}+\epsilon_{G}^{H, B} \\
E\left(U_{G}^{H, G}\right) / P_{G}^{H, G} & =\mu_{G}^{H, G}+\frac{1-P_{G}^{H, G}}{P_{G}^{H, G}} \mu_{G}^{o}+\epsilon_{G}^{H, G} \\
E\left(U_{G}^{o}\right) & =\mu_{G}^{o}+\epsilon_{G}^{o}
\end{aligned}
$$

Again, with searching in the new teacher market as the anchor,

$$
P(L, B \mid G)=\frac{\exp \left(\mu_{G}^{L, B}+\left(\frac{1}{P_{G}^{L, B}}-2\right) \mu_{G}^{o}\right)}{1+\sum_{j, k} \exp \left(\mu_{G}^{j, k}+\left(\frac{1}{P_{G}^{j, k}}-2\right) \mu_{G}^{o}\right)}
$$

Therefore, once again, all terms are identified (except utility of matching with new teachers).

\section{Policy simulation instructions}

Case 1: Decrease vacancies at good schools.

The simulation is conducted in the following way:

1. Total number of positions available for vacancies at good schools is decreased by 15 percent $\left(O_{k, n e w}\right)$, which is roughly fraction of the number of teaching positions in Charlotte-Mecklenburg over the total number of positions available.

2. Teacher search and utility parameters, school utility parameters, as well as matching parameters are kept constant.

3. I start with the original estimated teacher search parameters, teacher search $\left(\gamma_{j, k^{o}}^{k}\right)$, and match $\left(P_{j, k^{o}}^{k}\right)$ probabilities to generate the total number of searching teachers from each teacher type $\left(\widehat{T_{j, k^{\circ}}^{k}}\right)$.

4. The teacher and school search probabilities $\left(\gamma_{j, k^{o}}^{k}\right.$ and $\gamma_{k}^{j, k^{o}}$, respectively), $\widehat{T_{j, k^{\circ}}^{k}}$, and the new vacancies $\left(O_{k, n e w}\right)$ are used to calculate new match probabilities $\left(\widehat{P_{j, k^{o}}^{k}}\right)$.

5. The new match probabilities are used in the multinomial logit framework for teachers and schools (along with utility parameters) to generate new search probabilities $\left(\widehat{\gamma_{j, k^{o}}^{k}}\right)$.

6. The new match and search probabilities are plugged into 3) to generate new numbers of searching teachers $\left(\widehat{\widehat{T_{j, k^{k}}^{k}}}\right)$.

7. This process is repeated until difference between $T_{j, k^{o}}^{k}$ from one iteration to the next converges to some $\eta$ where $\eta \rightarrow 0$. 
Case 2: Increase the utility of matching with a bad school.

The simulation is conducted in the following way:

1. The constant term in the utility of matching with a bad school is decreased (in absolute terms) by 20 percent.

2. The remaining teacher search and utility parameters, school utility parameters, as well as matching parameters are kept constant.

3. I start with the original estimated teacher search parameters, teacher search $\left(\gamma_{j, k^{o}}^{k}\right)$ and match $\left(P_{j, k^{o}}^{k}\right)$ probabilities to generate the total number of searching teachers from each teacher type $\left(\widehat{T_{j, k^{k}}^{k}}\right)$.

4. The teacher and school search probabilities $\left(\gamma_{j, k^{o}}^{k}\right.$ and $\gamma_{k}^{j, k^{o}}$, respectively), $\widehat{T_{j, k^{k}}^{k}}$, and vacancies $\left(O_{k}\right)$ are used to calculate new match probabilities $\left(\widehat{P_{j, k^{k}}^{k}}\right)$.

5. The new match probabilities are used in the multinomial logit framework for teachers and schools (along with the altered utility parameters) to generate new search probabilities $\left(\widehat{\gamma_{j, k^{o}}^{k}}\right)$.

6. The new match and search probabilities are plugged into 3) to generate new numbers of searching teachers $\left(\widehat{\widehat{T_{j, k^{k}}^{k}}}\right)$.

7. This process is repeated until difference between $T_{j, k^{o}}^{k}$ from one iteration to the next converges to some $\eta$ where $\eta \rightarrow 0$.

\section{Abbreviations}

WCS: Working conditions survey; MSE: Maximum score estimators; NCLB: No child left behind act of 2001; NC: North Carolina.

\section{Competing interests}

The IZA Journal of Labor Economics is committed to the IZA Guiding Principles of Research Integrity. The author declares that he has observed these principles.

\section{Acknowledgments}

I thank Peter Arcidiacono, Justin Trogdon, Jake Vigdor, seminar participants at University of Kentucky and Sogang University, and an anonymous referee for helpful comments. I am grateful to the Center for Child and Family Policy at the Sanford School of Public Policy at Duke University for access to the NCDPI data set. All remaining errors are my own.

Responsible editor: Pierre Cahuc

Received: 4 December 2014 Accepted: 29 January 2015

Published online: 21 March 2015

\section{References}

Ahn T (2013) The Missing Link: Estimating the Impact of Incentives on Teacher Effort and Instructional Effectiveness Using Teacher Accountability Legislation Data. J Human Capital 7(3):230-273

Ahn T, Vigdor J (2014) The Impact of NCLB's Accountability Sanctions on School Performance: Regression Discontinuity Evidence from North Carolina. NBER Working Paper:20511

Arcidiacono P, Beauchamp A, McElroy M (2010) Competing for the Opposite Sex: An Equilibrium Model of High School Dating. Working Paper

Ballou D (1999) The New York City Teachers' Union Contract: Shackling Principals' Leadership. Center for Civic Innovation, Manhattan Institute. No. 6

Boyd D, Lankford H, Loeb S, Wyckoff J (2002) The Draw of Home: How Teachers' Preferences for Proximity Disadvantage Urban Schools. J Policy Anal Manage 24(1):113-132

Boyd, D, Lankford H, Loeb S, Wyckoff J (2011) The Role of Teacher Quality in Retention and Hiring: Using Applications-to-Transfer to Uncover Preferences of Teachers and Schools. J Policy Anal Manage 30(1):88-110

Boyd D, Lankford H, Loeb S, Wyckoff J (2013) Analyzing Determinants of the Matching of Public School Teachers to Jobs: Estimating Compensating Differentials in Imperfect Labor Markets. J Labor Econ 31(1):83-117

Brewer DJ (1996) Career paths and quit decisions: Evidence from teaching. J Labor Econ 14(2):313-339

Clotfelter C, Glennie E, Ladd H, Vigdor J (2008) Would higher salaries keep teachers in hight poverty schools? Evidence for a policy intervention in North Carolina. J Public Econ 92(5-6):1352-1370 
Dolton PJ, van der Klaaw W (1999) The turnover of teachers: A competing risks explanation. Rev Econ Stat 81(3):543-552 Fox J (2010) Estimating Matching Games with Transfers. Working Paper

Goldhaber D, Anthony E (2007) Can Teacher Quality be Effectively Assessed? National Board Certification as a Signal of Effective Teaching. Rev Econ Stat 89(1):134-150

Helms AD (2005) Fewer schools available for teacher transfers. Charlotte Dispatch retrieved from http://www.nctq.org/ nctq/research/1110394921293.pdf

Jackson CK (2013) Match Quality, Worker Productivity, and Worker Mobility: Direct Evidence From Teachers. Rev Environ Stat 95(4):1096-1116

Jacob B (2010) The Effect of Employment Protection on Worker Effort: Evidence from Public Schooling. NBER Working Paper 15655

Levin J, Mulhern J, Schunck J (2005) Unintended Consequences: The Case for Reforming the Staffing Rules in Urban Teachers Union Contracts. The New Teacher Project

Medina J (2014) Judge Rejects Teacher Tenure for California. New York Times June 10. (www.nytimes.com/2014/06/11/us/california-teacher-tenure-laws-ruled-unconstitutional.html)

Murnane RJ, Singer JD, Willett JB (1989) The influences of salaries and "opportunity costs" on teachers' career choices: Evidence from North Carolina. Harvard Educational Rev 59(3):325-346

Nelson F (2006) The Impact of Collective Bargaining on Teacher Transfer Rates in Urban High-Poverty Schools. American Federation of Teachers

Rickman BD, Parker CD (1990) Alternative wages and teacher mobility: A human capital approach. Econ Educ Rev 9(1):73-79

Rivkin S, Hanushek E, Kain J (2005) Teachers, Schools, and Academic Achievement. Econometrica 73:417-458

Rockoff J (2004) The Impact of Individual Teachers on Student Achievement: Evidence from Panel Data. Am Econ Rev 94(2):247-252

Stinebrickner TR (2001) A Dynamic Model of Teacher Labor Supply. J Labor Econ 19:196-230

van der Klaauw W (2012) On the Use of Expectations Data in Estimating Structural Dynamic Models: An Analysis of Career Choices. J Labor Econ 30(3):521-554

Winkler AM, Scull J, Zeehandelaar D (2012) How Strong Are US Teacher Unions? A State-by-State Comparison. Thomas B. Fordham Institute

\section{Submit your manuscript to a SpringerOpen ${ }^{\circ}$ journal and benefit from:}

- Convenient online submission

- Rigorous peer review

- Immediate publication on acceptance

- Open access: articles freely available online

- High visibility within the field

Retaining the copyright to your article

Submit your next manuscript at $\gg$ springeropen.com 